Exploring the socio-cultural contexts of fishers and fishing: developing the concept of the 'good fisher'

The published version of this paper (with figures) can be found at:

http://dx.doi.org/10.1016/i.jrurstud.2016.12.012

Please cite as:

Gustavsson, M., Riley, M., Morrissey, K., \& Plater, A. J. (2017). Exploring the socio cultural contexts of fishers and fishing: Developing the concept of the 'good fisher'. Journal of Rural Studies, 50, pp. 104-116. 


\title{
Exploring the socio-cultural contexts of fishers and fishing: developing the concept of the 'good fisher'
}

\begin{abstract}
Recent calls have been made to pay greater attention to the social and cultural contexts of fisheries and their management. This paper explores how the recent Bourdieusian-inspired literature on the 'good farmer' might inform our discussion of fishers and their activities. Bourdieu's ideas of habitus, field and capital(s), and how these interact in (re)shaping the positioning as a 'good fisher', allows us to move beyond the myopic, economic, framing of fishers seen in much previous literature and fishing policy. Through in-depth interviews and participant observations in a small-scale fishing community in North Wales (UK), the paper explores the particularity of the fishing field, and notes the multiple performances and demonstrations required in order for individuals to position as a 'good fisher'. It goes on to highlight the importance of these performances in developing social capital and the associated access to networks of support and reciprocity at sea. Central to these interrelations, the paper observes, is adhering to and internalising various 'rules of the game' - which include managing territories, respecting fishing gear, maintaining safety at sea, and the importance of keeping secrets. The paper moves on to consider the implications of these observations for the current and future management of fishing in such areas - noting how pre-existing and context-specific relations between fishers offer boundaries to what change might be achieved by new policies - before examining future agendas for research in this field.
\end{abstract}

Key words: The good fisher; social capital; Bourdieu, fishing community; the sea.

\section{Introduction}

In recent years there has been a call for a greater application of insights from social science to the discussion of fishing and the fishing industry. As Urquhart et al (2011, p.420) suggest: "while much is known about the ecological and economic aspects of fisheries, the social and cultural impacts of fisheries and their management has been under-researched and is often overlooked in policy". Such a call has been set against the backdrop of a turbulent recent history for the fishing industry stemming from concerns for fish stock resulting from overfishing (Costello et al.,2012), the economic decline of the 'fishing industry' and what the 
attendant 'post-productive' coastal settings might look like (Salmi,2015), as well as the subsequent calls to safeguard this industry (DEFRA 2007). As Sønvisen (2014, p.194) has recently argued in the pages of this journal, a particular weakness of much pre-existing fisheries research has been the tendency to depict fishers ${ }^{1}$ as "myopic and short-run profit maximizers", which arguably ignores the complexity, diversity and dynamicity in the behaviour of fishers (see also Nightingale,2011; St Martin,2007). Although they recognise a growth in research which has sought to contradict these prevailing models, they conclude that the "operating assumption of homogeneity among fishers prevails in fisheries management systems" (Sønvisen,2014, p.194). As several authors have noted, such assumptions - which fail to fully understand the social and cultural contexts in which fishers actually operate - are likely to limit what can be achieved by fishing policy (Davies and Hodge,2007).

This recognition of the need for a conceptual apparatus which moves us beyond a purely economic depiction of fishers has striking parallels to the literature on farming and agriculture. For several years now rural and agricultural social scientists have forged similar debates with several innovative approaches which have sought a consideration of farmers as more than 'rational' homo economicus and which takes fuller account of the social and cultural contexts which can serve to shape their activities (see Riley,2011). Arguably there is much which might be learned, for the consideration of fishers, from this more voluminous literature on agriculture and some useful cross-fertilisation can already be noted. Boonstra and Hentati-Sundberg (2014), for example, deploy the idea of 'fishing styles' which echoes that more long-standing work on farming styles (see Van der Ploeg,2003); Sønvisen (2014) draws on typology, or the study of types, that has been successfully applied in the discussion of agriculture (Whatmore et al.,1987); Urquhart and Acott (2013), in their discussion of occupational identity, highlight the parallels with discussions of occupational identity in times of structural change within agriculture (Brandth and Haugen,2011); whilst earlier work on farmers environmental attitudes and perceptions of farmers to environmental schemes (e.g. Morris and Potter,1995) has been taken forward in considering how fishers adapt (or not) to new marine policy (Gelcich et al.,2008). The following paper seeks to draw into this

\footnotetext{
${ }^{1}$ Although all of those spoken to in this research self-defined as 'fishermen', in this paper we use the more gender-inclusive term of 'fisher'. Branch and Kleiber (2015) have recently offered a detailed discussion of how such choices of terminology may be interpreted as processes of inclusion and validation, or exclusion and disrespect depending on the context. Whilst the voices in this paper are predominantly those of men, we do not wish to foreclose the possibility that in other geographical contexts, where our findings here may have relevance, that it may be women who perform these roles and activities.
} 
discussion of fishers and fishing the ideas of Pierre Bourdieu relating to habitus, capital, field and 'rules of the game'. Specifically, it seeks to forge a critical dialogue between the case of fishers and the growing body of work, drawing on Bourdieu, which might be termed the 'good farmer' literature (Burton et al.,2008; Burton,2004; Sutherland and Burton,2011).

Within the literature on the 'good farmer', the discussion of how a farmer's social position and status is impacted upon by their adherence "to a set of principles based on values and standards embedded in farming culture" (Sutherland and Darnhofer,2012, p.232) has been a fruitful avenue of social science research and a survey of this literature highlights three key insights which it might offer the discussion of fishers. First, and foremost, this literature moves beyond a focus on economic capital to also give account to social capital (stemming from, and reaffirmed by, social contacts) and cultural capital (skills, knowledge and dispositions which may be gained by education and socialisation). In addition, attention is given to symbolic capital, which is the form that these other types of capital might take on when they are "perceived and recognised as legitimate" (Bourdieu,1989, p.17) within a particular field. Second, it recognises the importance of the surrounding community - with the farming community generally, and farming neighbours specifically, providing the conduit through which capital is built up, exchanged and policed (Sutherland and Burton,2011). Third, this body of research has been useful in its application to the discussion of wider structural changes and changing agricultural policy. So, for example, research employing this framework has considered both how new agricultural policies - such as agri-environment schemes - may be rendered 'culturally unsustainable' (Burton et al.,2008) when in conflict with pre-existing notions of good farming, as well as the wider discussion of whether changing structural conditions may change the farming habitus and what it is to be a 'good farmer' (Riley,2016a; Sutherland and Darnhofer,2012).

Although this work on the good farmer offers clear potential, it is important to note at the outset that fundamental, as well more subtle, differences between fishing and farming need accounting for when attempting this cross-pollination of ideas. These differences stem in large part from the structures of owership and the particular materiality of the sea. Whilst farming is clearly, and often literally, demarcated in terms of ownership and mangement patterns, the sea is more complex. Historically depicted as a common resource it has become, some commentators suggest, "owned by no-one in particular but managed by the state in trust for its citizens" as access rights have been eroded via a succession of licensing, quota restrictions and rights based management (Symes and Phillipson,2009,p.2). More 
fundamentally, in distinction to the fixity of farmland, the mobility and fluidity of the sea mean that it is "an active participant in the politics of its management" (Bear,2012, p.8) providing challenges of access, visibility and management (both from an exploitation as well as conservatoin standpoint) - as Bear (2012, p.15) observes: "boundaries are drawn on maps to determine where certain activities may or may not take place, but the materiality of the [sea] does not necessarily respect the boundaries". Drawing on indepth qualitative research on the Llŷn peninsula in Wales (UK) the aim of the following paper is to explore how ideas from the good farmer literature can be usefully utilised and (re)shaped to the discusison of fishing and fishers. Following a consideration of current trends in the social science literature relating to fishing, the paper outlines the key tenets of the good farming literature, before examining how this relates to, and might be rethought in relation to, our specific study of fishers in the Llŷn peninsula. The paper then moves on to outline the wider relevance of these findings and suggest potential avenues for future research.

\section{Conceptualising the 'good fisher'}

\subsection{Social science research and fishers}

In surveying the past research on fisheries, it has been suggested that biological and economic perspectives have tended to dominate discourses of fisheries management (Symes and Hoefnagel,2010; Urquhart and Acott,2013). Although, prior to the late 1980s, there were examples, particularly from anthropology, which employed more in-depth ethnographic approaches to researching fisheries (Acheson,1981), it has been argued that the pursuit of 'policy-relevant' research meant that more socially-orientated perspectives tended to become marginalized (Symes and Phillipson,2009) with little attention paid to the "social organization of fishing and its importance in fisheries management contexts" (van Ginkel,2014, p.2). Nonetheless, social science research has made an impact on the wider discussion of fishing dynamics, with one of the most voluminous contributions coming under what might be termed the 'common property resource' literature (see McCay and Acehson 1987). Seeking to act as a corrective to Hardin's (1968) notion of the 'tragedy of the commons' - which has underpinned the aforementioned 'bio-economic' perspectives within fisheries management - this research has provided empirical evidence to suggest that fishers are able, under certain institutional conditions, to self-organise for collective good rather than just for individual benefit (McCay and Acheson,1987; Ostrom,1990; Pomeroy and Berkes,1997; St Martin,2006). Jentoft and Davis (1993), for example, add nuance to this 
discussion by calling for a move beyond essentialist depictions of fishers, to recognizing how different types of individualism (the 'rugged individualist' and the 'utilitarian individualist' in their study) might facilitate different forms of group engagement and cooperative behavior - but like many studies in this arena they suggest that a mediator is often required for successful cooperative action. This latter point has been taken forward in recent critiques which have argued that self-organisation and self-governance is often sporadic and unreliable in relation to contemporary sustainability policy and that attempts to govern one part of the system might lead to unintended acts of self-organisation in other parts (de la Torre-Castro and Lindström 2010). In moving forward these reflections on the common resource literature, Nightingale $(2011 ; 2013)$ has recently called for a more diverse framing which recognises not only the institutional determinants of cooperation, but moves towards a clearer recognition of the non-institutional, context-specific social relations and commitments - what she refers to as the 'irrational commons' - which oblige fishers to cooperate (or not). As Symes and Hoefnagel (2010, p.269) concur: "the emphasis on institutional development coincides with a neglect of community studies through which the economic and social consequences of fisheries policy are refracted and adaptive strategies best examined".

In relation to the parallel recent call to give closer attention to what social science might offer the discussion of fishing and fishers (Urquhart et al.,2011) several useful trajectories can be traced. Williams (2014), for example, considers the socio-cultural impacts of restructuring of the fishing industry, exploring how collective identities within the fishing community have lost their sites of performance(s) and symbolic importance in place. Others have drawn on social theory in an attempt to unpack the notion of fishing 'community' - a term often drawn upon in the media and political attention given to fisheries. Ross (2015), in this vein, conceptualises the fishing community, not as a spatial unit, but as a 'community of the mind', and illustrates how empathy and networks of support allowing a resilience amongst fishing communities in the face of change and uncertainty. Taking a longer temporal perspective, Martindale (2014) explores the importance of heritage and history for fishing communities of today by studying crafts and livelihoods in Cornwall. Reed et al (2013) similarly examine recent changes to fishing and suggest that inshore fishing, beyond creating job opportunities, is significant to place identities tied to the fishing occupation. In particular, they suggest that strengthening the links between food and locality by making local fish available and fostering diversified preferences amongst consumers would build more sustainable inshore fishing communities. 
A variety of recent contributions have been made which have broadened the focus beyond fishers, to recognise the wider networked and material relations of which they are part. Useful to our discussion here are those studies which have considered the (im)materiality of the sea and sea life, which bring together insights from Actor-Network Theory (ANT) and assemblage theory to trace how the sea's fluidity and flows create particular spaces (or waterscapes) which shape the interactions between the human and nonhuman (Bear,2012; Bull,2011). Eden and Bear's (2011) exploration of anglers is informative, showing that the depth of marine environments distinguish them from those of agriculture as it serves to render fish invisible and highlights how fishers come to know fish through other proxies such as temperature profiles and channel morphology. Bull (2011) pushes these ideas of materiality and understanding further by noting how an awareness comes not only through experiential engagement 'on the water', but through interactions with other fishers in spaces such as the shore and the pub. Taken together, such studies remind us how fishing is a complex socioecological entanglement and an exploration of the social relations cannot be read in isolation from these material realities.

Important across the aforementioned studies is a recognition of the heterogeneity of fishing communities and the temporally dynamic nature of the industry. In their studies, Sønvinsen (2014) and Boonstra and Hentati-Sundbergs (2014) attempt to offer some level of classification in the discussion of fisher 'types' and 'styles' respectively. Sønvinsen (2014) uses Multiple Correspondence Analysis and fishers' discourses to develop a fourfold typology - two types linked to ideology and two linked to pragmatism - with the result being a call to revise fishing policy to better target this diversity in perspectives. Boonstra and Hentati-Sundbergs (2014) make a similar call, and through an integration of quantitative classifications and qualitative analyses identify several fishing styles which, they suggest, may allow for some level of generalisation of fishers' behaviour without negating the individual differences that may be part of this. The collective relevance of these studies for our purposes in this paper, is the recognition that fishing is historically, socially and geographically situated. The actions of fishers, be that in relation to others or wider restructuring, is not simply reducible to economic transactions and a more nuanced framing is required which takes on board these social relations alongside the shifting institutional contexts in which fishers operate. 


\subsection{Learning from the 'good farmer'}

In moving the discussion of farming beyond a myopic consideration of its economic aspects, Bourdieu's (1998, p.vii) conceptualisation of the social world as a "two-way relationship between objective structures (those of social fields) and incorporated structures (those of the habitus)" has been drawn upon within the good farmer literature and provides a useful blueprint through which we might also consider fishing. Bourdieu (1998, p.81) refers to habitus as the disposition to act within "a particular section of the world - a field - and which structures the perception of that world as well as action within that world." Research within farming has considered how behaviours may become consistent when farmers recognise and internalise the 'rules of the game' within that particular field (Richards, 1993). ${ }^{2}$ That is, farmers with a similar habitus give similar value and meaning to symbols seen as being associated with being a 'good farmer' (Saunders,2015; Sutherland,2013) and, following Bourdieu's (1986) logic, these can be used to (re)position within the particular field. Accordingly, one of Bourdieu's ideas which has been drawn down on most within the good farmer literature is that relating to capital(s). As suggested in our introduction, in addition to economic capital, Bourdieu draws attention to the importance of other forms of capital social, cultural and symbolic. Cultural capital has been a key focus in the discussion of the good farmer (see Burton 2004), with attention paid to its three main forms: institutional (certification of cultural competency), objectified (high status value material objects) or embodied ("in the form of long-standing dispositions of the mind and body" (Bourdieu 1986, p.47)). Within the good farmer literature, the certification of cultural competence has been exemplified in the discussion of breed societies (Holloway 2005; Yarwood \& Evans 2006) with objective cultural capital being understood as materialised through ownership of farms and farming machinery (Holloway,2004; Sutherland and Burton,2011) and the quality of livestock and crops (Burton,2004). In expanding further on the notion of objectified cultural capital Burton et al (2008, p.19) suggest that the:

"value is not in the object itself (which could be obtained through a simple financial transaction), but is instead dependent on its use in accordance with a specific purpose, as actioned through the embodied cultural capital of the agent."

\footnotetext{
${ }^{2}$ Richards $(1989,1993)$ seeks to push these ideas further in bringing in the discussion of 'performance' to examine how farmers react deftly to changing circumstances (including changing weather and technology failure).
} 
Important, therefore, is having the skill to action this capital - or as Sutherland (2013) notes, having the appropriate reactions to typical circumstances (Richards,1993). Burton et al (2008) offer a finer analysis in breaking down this skill, for farmers, into mechanical, motoric and managerial - each of which is central to an individual's project of 'self-improvement' and position within the field of farming. In this context, mechanical abilities include those associated with the maintenance of farming machinery for example, motoric skill refers to abilities such as being able to skilfully handle machinery as well as having 'attention to detail' and managerial skill is the ability to 'do the right thing at the right time' (Burton et al. 2008) - a theme which has also been observed in other geographical contexts (see Sumberg,2011). For these three abilities to become known as symbols of 'good farming' three conditions, according to Burton et al (2008), need to be present: i) the activities must reflect a skilled performance easily understood as 'poor' or 'good' performances ii) the skill must be manifested in the outcome of activity - that is, an outward sign of the skilled performance must be present iii) the outward signs must be visible or otherwise accessible to the farming community. A useful extension of this literature is that which has focussed more fully on farmers' interactions with each other, which notes that the subject position of the good farmer is not only built through display of embodied cultural capital, but also through a farmer's "reputation for complying with unwritten reciprocal agreements" (Sutherland and Burton 2011, p.249). Having such a reputation, they found, was embodied as social capital in the form of access to machinery and reciprocal labour exchanges with other farmers. Important within the Bourdieusian literature is cyclical relationship between capital(s), habitus and field (Crossley,2001). The good farmer literature offers a framework pertaining to these interrelations which, in the analysis that follows, we can use to explore the distinct field of fishing.

\section{Methodology}

This paper is drawn from a study on the Llŷn peninsula - a small-scale fishing area in North Wales (see Figure 1) - and utilises in-depth qualitative interviews (conducted in 2014/2015) with 47 participants linked to 14 different fishing vessels from various locations around the peninsula. The Llŷn peninsula was selected as a site of study for two main reasons. First, its smaller-scale nature (i.e. vessels are under $10 \mathrm{~m}$ (see Figure 2)). ${ }^{3}$ Although it is recognised

\footnotetext{
${ }^{3}$ The Welsh fishery has, generally, a higher proportion of small-scale boats (under $10 \mathrm{~m}$ ) than the rest of the UK and $32 \%$ of the fleet are part-time fishers (MMO 2015).
} 
that there is great diversity in fishing types and locality, smaller-scale enterprises are still seen as making up a significant percentage of the industry in Europe (Guyader et al.,2013). Second, the area has recently been subject to an attempt to introduce a Marine Conservation Zones (MCZ), which brought public opposition and was eventually scrapped. ${ }^{4}$ The Llŷn peninsula fishery is known as a multi-species, multi-gear coastal fishery and lobster, crab, scallops, whelks and sea bass were the main target species. Amongst those interviewed, all can be classified as lobster fishers who, to varying degrees, engage in targeting other types of fish and shellfish using other fishing gear. ${ }^{5}$ The fishery is seasonal with a combination of both part-time and full-time fishers.

Although the study incorporated the lives of and contributions of women to fishing families and the fishing industry, the data presented here focusses specifically on the actual practices of fishing, which in this locality were undertaken by men. The age of the male fishers interviewed range from 18 to 75 but the majority were between 30 and 60 . The majority of fishers spoken to were Welsh ${ }^{6}$ and came from families who had fished in the area for more than one generation. Several of those interviewed held positions of importance in local, regional and national fisheries organisations. The fishers were a combination of both parttime and full-time fishers, fishing out of small 'fishing coves', or moorings in protected bays, without access to harbour facilities (see Figure 3). To support themselves economically, fulltime fishers often had intensified their fishing operation, employed alternative fishing methods and/or diversified their fishing products. Part-time fishers, on the other hand, often had a second jobs in industries such as construction, tourism and farming as well as in the public sector.

[Figure 1 around here]

[Figure 2 around here]

[Figure 3 around here]

Initial contact was made with two local fisheries committees, with members providing a first wave of respondents, and chain-referral sampling (Heckathorn,2002) used to locate subsequent waves. The interviews were qualitative and semi-structured, aimed at gaining a

\footnotetext{
${ }^{4}$ Source: Letter to the Welsh assembly Marine Branch by CRAGED Llŷn a Môn dated $31^{\text {st }}$ of July 2012.

${ }^{5}$ Given the small scale nature of this fishery, specific details of fishing activities/distributions of each individual are not given in order to maintain their respective anonymity.

${ }^{6}$ The fishers predominantly spoke Welsh but interviews were conducted in English.
} 
deeper understanding of fishers' activities, knowledges, identities and interactions as well as a specific focus on how they defined 'good' fishing. The interview approaches included individual and joint interviews (with other fishers or family members) and repeat interviews where possible. The interviews took place in locations of respondents' own choosing - most commonly in their homes and/or in close proximity to the fishing cove - and offered the practical advantage of fitting around their busy schedules as well as providing material objects to feed into the discussion, including things such as photographs, fishing gear and the cove itself. Alongside the interviews, several weeks of participant observations were undertaken in ashore spaces - observing interactions with others, fishing and associated work, as well as fishers' activities and performances in particular places. Interviews lasted between 45 minutes and 2 hours, were recorded and transcribed verbatim. The transcripts were coded manually and the following sections represent the emergent themes from the thematic narrative analysis (Riessman,2008) of this data.

\subsection{From the 'field' to the sea - seeing and demonstrating skill}

Most often focussed on in research on the good farmer has been objectified cultural capital, which is perhaps unsurprising as this is most common in material forms which the researcher can overtly observe and, through illustration, is easiest for respondents to articulate to researchers. The interviews revealed that the nature of the field of fishing made the demonstration and articulation of this objectified cultural capital more complicated for fishers. Although, as we will discuss later in the paper, there may be rules around fishing 'territories'(Symes and Frangoudes,2001), the lack of direct ownership means that the sea does not stand as objectified cultural capital in the same way as farm ownership and thus other forms of capital demonstration are required. As Burton (2004) notes, skill needs to be outwardly available to others and in farming this commonly happens through what he terms 'hedgerow farming', whereby neighbours and other farmers survey the efforts of the respective farmers. Accordingly, high status items such as livestock and high crop yields - or what might be termed 'symbols of production' (Burton et al.,2008) - become important visible signs through which they might gain symbolic capital. By contrast, the less static nature of the sea (see alsoBear,2012) means that it is not able to stand as a visible, permanent, embodiment of the outcome of fishers' work, whilst the moving and offshore nature of fishers' activities mean that they may neither be clearly visible from ashore nor as easy to decipher. 
In broadening this discussion of the visibility of skill, Sutherland notes (2013, p.432 emphasis added) for farming "skill must be visible or otherwise accessible to the other members of the farming community". The interviews revealed that for the fishers, the placing of buoys above the sea surface was one way that evidence of fishing skill becomes available to others. Each fisher interviewed had their own individual mark (usually indicated by a particular colour) on their buoys making it possible for others to know who has performed a particular activity. One fisher explained:

Interviewer: "How would you know [if other fishers are successful]?

"If you didn't see what they're actually physically landing... You can see the way the fishing gear, the way they move it around the bay. The way they fish and their style of fishing you'll think 'well, he is going to be catching pretty well' [...] the times of the year, where they are... and you get other people who are completely random doing it, just all over the shop. But you could tell without physically seeing what they catch, I suppose... [there] are variables..." (F-16).

Fisher 16's narrative reveals that although directly observable indicators of production success are not available to fishers in the same way as for farming, this does not mean observations and associated judgements do not occur. Instead, the observations are akin to those of 'straight lines' within crop planting that have been noted in the good farming literature (Burton et al.,2008; Riley,2016a), whereby it is a practice associated with good production, or in this case a fisher's good catch, rather than the output itself, which is observed. Here, these are not only a demonstration of motoric skill - their placing and spacing being a skill in itself - but also evidence of the managerial skills of knowing when to apply context-specific appropriate actions. Their use and placing thus becomes taken as a proxy for successful fishing. Although crops and livestock, as signs of farming skill, are visible to a wide variety of onlookers - both farming neighbours and beyond - for fishing the display of buoys on the water have a smaller group of observers. This relates both to their offshore locality, but also in terms of those who are able to decode their significance and relevance. As fisher 16's narrative shows it is necessary to understand, himself, what he refers to as the 'variables' - such as the likely catch in that particular tract of the sea and the impacting weather conditions at that particular time - in order to understand the skill, or otherwise, that the buoys embody. 
This example of the buoys sits alongside the wider theme of 'fishing gear' which, interviews revealed, were integral to being afforded the status of a good fisher. Similar to the example of farm machinery, this gear carried both material ${ }^{7}$ value and symbolic value. Fisher 22 revealed that not only was having possession of this form of objectified cultural capital important, but so too was ensuring that it was maintained and kept hold of:

"predicting the weather, getting it right, when you move your gear close inshore, then moving them out before a gale. You have gotta be on the ball with things like that. You can't be lazy. [...] And if I do lose gear I am really pissed off, there has been a mistake or I misjudged the weather" (F-22).

Observations from those such as fisher 22 echo the view that objectified cultural capital needs to be actioned through the embodied cultural capital of the agent (cf. Burton et al.,2008). So, in this case, it is not only having a number of pots that is central to the positioning as a good fisher (objectified cultural capital), but the associated skill of predicting and working with the weather so as to use the pots effectively without needing to replace them (through loss or damage). This was expanded upon in the same interview, where fisher 22 observed that:

"[There is] a saying "any fool can carry money to the sea" [...] anyone can invest in a big boat, lots of lobster gear but you have got to return a profit [...] it is not a hobby" (F-22).

For this fisher, similar to several others interviewed, objectified cultural capital on its own, in the form of expensive boats and gear, was insufficient to be afforded the status of 'good fisher'. Indeed, like Burton's (2004) reference relating to farming on the purchase of machinery which might be seen as too economically large for its purpose, such possession of expensive fishing equipment, without the necessary skill to handle it effectively, may serve to negatively affect a fisher's status and credibility. This also has important implications for our broader understanding of fishing in that although economic status is one measurement of their status in the field, it also illustrates that it is possible to have high value goods and not evoke the standing as a good fisher - something which is important for the reciprocal arrangements of fishing that we will discuss later in the paper.

Perhaps more so than noted in the good farming literature, the interviews revealed that this connection between skill and equipment was an intricate and iterative relationship. Many

\footnotetext{
${ }^{7}$ Some of the boats reported on cost in excess of $£ 100,000$ pounds and fishing gear $£ 50,000$ (F-16).
} 
fishers referred to how their boats were part of their skill development and refinement. Two extracts are illustrative here:

"Using the boat, really you get intimate knowledge of the fishing ground, the patch, the weather conditions. [...] You know, when you can go out, when can't you go out. [...] the understanding of the tides and the seasons and how to fish, when to fish, where you fish. What is the best method, the best bait" (F-22).

"Being able to handle a boat single handed is quite an achievement. [...] Especially, our size boats they are quite big and heavy. [...] We have to launch ours (see Figure 2), we can't moor. [They] have to be hauled in and out, which is hard work. [...] There is skill [...] You have to be able to do everything. [...] You learn as you go along. [...] You just progress" (F-19).

Both extracts reveal that for fishers, their connection to their equipment, and boats in particular, is the main way through which they come to experience the field of the sea. As Palsson (1994, p.910) has previously noted: "the skilful skipper attends to his fishing technology as if it were an extension of his person". The fluidity of the sea and the marine environment is central to this relationship. Whilst farmers might walk their land and map (both literally and mentally) its characteristics and variations - fixing its properties and allowing a more cumulative layering of knowledge of it over time ${ }^{8}$ - for fishers the constantly changing nature of the sea makes this more difficult. Although most fishers pointed to their knowledge of the coves and tidal patterns of the areas they fished, this was in all cases accompanied by a clear and forceful recognition of the unpredictability of this terrain. The demonstration of embodied cultural capital - in this case the skill of handling boats - was something, therefore, which was constantly being (re)demonstrated in the moment. The changing nature of weather patterns, tides and catch activity mean that rarely are two situations, and hence the skills demonstrated within them, the same. Whilst the successful 'handling' of equipment in agriculture includes the ability to work with precision, such as in the careful sowing of crops or in the judicious application of fertilizers and pesticides - themselves often repetitive activities - the skilled handling of machinery for fishing involves the added necessity of being able to react, change course or alter strategy at short notice.

\footnotetext{
${ }^{8}$ See Riley (2008) for a discussion of these place-specific knowledge cultures which farmers may develop over time.
} 
Alongside the motoric skill of handling boats, mechanical abilities were also commonly referred to by the fishers spoken to. The two following quotes reflect two aspects to this which emerged in the interviews:

"Since I got my own boat. Oh my god it has blown my mind, how you gotta be a mechanic, an electrician, an engineer and a skipper, and answer the phone-a secretary" (F-11).

"Cause we have to build our own trailers, [...] we have to be welders, we have to be fishermen, you name it we have to do it. [...] engineers. If the engine conks out you have to be able to repair it, [...] rebuild an engine, [...] it is all part of it. So you have to be a mechanic as well. [...] Navigation too [...] you have to be everything-except a millionaire" (F-19).

The ability to undertake maintenance and make and repair equipment were central aspects of being a good fisher amongst all of those spoken to. At one level, there was a safety element to this - with fishers noting the necessity to understand the mechanics of their boat in order to fix it in the event of breaking down whilst at sea. At a second, and interrelated level, was the notion of independence. As fisher 19 noted, there is an element of economic capital within this, with profit margins tight and thus a need to minimise spend on external labour. Interlinked with this was the need to demonstrate self-sufficiency within being a good fisher. ${ }^{9}$ Skill, in this sense, was not just seen to be in the direct activity of landing catch - evidenced in the arrangement of buoys referred to earlier - but in showing a range of different skills which, collectively, facilitate a level of autonomy for each fisher. Finally, as fisher 19 makes reference to, the standard of their equipment is taken, by other fishers, as an indirect marker of their ability to catch. In this context it becomes a sign of their catching and good fishing abilities. In large part, this was due to the associated perception of readiness, whereby a fisher was ready to take advantage - at any time - of a change in the weather or catch movement in order to land a good catch.

\subsection{Working together and working with the sea}

\footnotetext{
${ }^{9}$ Whilst equipment carries capital value in both fishing and agriculture, the 'technology treadmill' noted in agriculture was less prevalent on the Llŷn peninsula as whilst fishers do invest in replacing and updating equipment their tendency, as Cambie et al (2015) have in other parts of Wales, is toward risk reduction and costreduction - evidenced in self-repair of equipment - rather than profit maximising through specialisation and larger investments.
} 
As noted in the previous section, the lack of clearly defined ownership structures and the particular nature of working with the sea serves to influence the fishing field generally (cf. Symes and Phillipson,2009), and the routes through which fishers may exhibit skills (or cultural capital) specifically. As noted earlier, Sutherland and Burton (2011) show that it is not only through displays of embodied cultural capital that reputation may be enhanced, but also their roles within reciprocal agreements with others. It was observed in the interviews with fishers that the lack of clear ownership boundaries actually raises the importance of these relationships with other fishers - reciprocal or otherwise - as they work in this common resource. The often paradoxical nature of this relationship was highlighted by fisher 11 who talks both about the competitive nature of his occupation and then, later in the same interview, the cooperative aspects of these relations:

"Yeah, there is always competition. [....]It is not a public competition but it is just in everybody's head [....] not many would admit to that but everybody knows that he wants to do better than you and you want to do better than him, you know, [...] it is like a game..." (F-11).

Then later in the same interview:

"We are all friends... we all get along. If anything happens to somebody or if you want to borrow a tool or something you just go alongside of each other and chuck it over. If somebody breaks down and you need a tow in, [...] everybody helps each other out [...] it is a close knit [community] [...] Everybody should look out for one another. [...] [There'll] be certain times in my life when I am definitely going to need some kind of help. [...] You scratch my back I scratch yours isn't it? I would never pass anybody, bloody hell no [...] cause I would expect the same you know" (F-11).

We can see here that fishing can be seen, at once, as both a cooperative and competitive industry. ${ }^{10}$ Within the good farming literature, it has been noted that competitiveness may be part of the social order, with social capital derived from how higher status cultural goods compare with those of neighbours and other farmers. ${ }^{11}$ However, at the level below this - the everyday working of their land, farmers are not competing per se-with each having their

\footnotetext{
${ }^{10}$ For an historical overview of this dual nature of fishing and a wider wider review of fisheries as common property see Pomeroy and Berkes (1997).

${ }^{11}$ Although not often focused on in the good farming literature, so too there is competition when land becomes available for purchase or rent.
} 
own defined territory and a resource not encroached on by others (cf.Ostrom,1990). ${ }^{12}$ For fishers, however, there is an inherent competition for resource - the sea and the associated catch. Fishing licenses mean that there is some level of formal arrangement of who can fish the sea, but the interviews revealed that where and how they did this was informed by the social relations between fishers. The interviews highlighted that the balancing of cooperation and competition was central to earning and maintaining the position as a good fisher and four specific themes recurred within interviews: managing territories, respecting fishing gear, safety at sea and, running through each of these, the importance of keeping secrets.

For the lobster and crab fishers spoken to in particular, territories were closely linked to themes of respect, "gentlemen's agreements" [sic] (F-8) and fishing history. The three following extracts describe the various facets of this system:

"We generally fish the same piece of area, but there are also little areas inside that that I don't go and he doesn't go" (F-16).

"We are all local fishermen, [...] we haven't got any problem really. Everybody knows the rules and stick to it. I don't go to their patch and they don't come to mine. [...] We have words if we do but yeah, [...] no it is fine" (F-19).

"It is not their patch obviously, it doesn't belong to them but it is just respect. It depends on where you have always fished. Most fishermen, especially around here, it's been handed down. [...] You know generation to generation” (F-28).

Fisher 19 makes reference to the 'rules' - or what in Bourdieusian terms might be called doxa - through which fishing territories are policed. The quotes from fisher 16 and fisher 28 go on to illustrate the ways in which these are spatially and temporally defined. Several fishers spoke of the importance of history and, as noted in the extract of fisher 28 , the importance of generational transfer. The interviews showed that a key difference to farming is that although fishers may inherit fishing equipment and boats from their predecessors, these are depreciating goods, as opposed to the transfer of land, seen in agriculture, which invariably increases in value (often exponentially) over time. Where a similarity can be drawn, however, is in how skills and knowledge are passed from one generation to another and shape the fishing habitus. Practically, the cultural capital associated with being a good fisher may be

\footnotetext{
${ }^{12}$ The obvious exception to this idea is the discussion of farming common land. For a detailed discussion of this see Wilson and Wilson (1997).
} 
accumulated through intergenerational transfer. Such generational transfer of capital, the research highlighted, was sufficient to make the fishing relationships, and associated access to fishing territories, relatively static. Whilst there are some subtle variations in how these sharing arrangements work, the general rule of "you keep out of my area, I'll keep out of yours" (F-28) worked well, the interviews revealed, with few instances of recurring conflicts reported on. Important within this process of intergenerational transfer, the interviews revealed, is the need for the incoming generation to demonstrate their good fisher skills from the outset. Whereas in farming the objectified cultural capital of the farm itself may be drawn on by younger generations, at least for a short period (Riley,2016b), in lieu of skill demonstrations, fishers to do not have this backdrop of ownership through which to exchange capital and maintain their good fisher status.

A second aspect relating to these rules on fishing territories is how good fishing may be seen as spatially specific and how this, in turn, serves to police the boundaries of fishing. Fisher 19 notes "we are local fishermen" and this is important for our broader understanding of the concept of the good fisher. Recent critiques of the good farming literature have focussed on the perceived underplaying of what might be regional variations in good farming and contextspecific symbols of good farming (Riley,2016a; Sutherland,2013). As the last section of the paper suggested, good fishing involves the demonstration of an awareness of the specific micro-climates of coves and stretches of water and, as fishers like fisher 22 demonstrate below, it is also about understanding the 'rules of the game'(Bourdieu,1984) in this particular locality:

“Outsiders you don't like, cause you can't trust them. [...] Some people from away you dislike because you know of them and they have a bad reputation. You know like, someone who takes like undersized lobster or whatever, they are idiots" (F-22).

'Outsiders', the interviews revealed, were both defined as not having a history in that area and, accordingly, not understanding the intricacies of the micro-climate. As a result, as fisher 22 reveals, they did not have sufficient accumulated social capital to afford them the trust of those 'local' fishers in the area - a theme returned to later in the paper. Three specific 'outsider' groups could be identified within interview responses. First, were what might be termed 'hobby fishers' who only had a small numbers of pots and used their catch for personal consumption. Such 'fishers', the interviews revealed, were cast as outsiders due to not having gone through the extensive socialisation process in building up the geographically 
specifically fishing capitals. Second, were larger-scale fishers whose outsiderness was defined both geographically and socially as they failed to have a biographical history in the area and lacked an understanding the micro-context and 'rules of the game' of this particular area. Third were those 'outsiders' who could be both geographical and commercial fishers but who did not live up to the 'good fishing' ideals of being skilful and complying with the unwritten rules of the game.

The importance of trust within fishing echoes a number of the observations made in the good farming literature. In a similar way to farming, the fishers revealed that it was something built up over time and illustrated how trustworthiness could feed directly into the level of social capital a fisher has. A common example used in interviews to articulate this trust was relying on others not to steal their catch from static gear or quay pots:

"Because it is all trust down there. You have got to keep your fish fresh for the week so you have got to put all your lobsters in the quay pots. [...] And sometimes they wonder if someone is going in them... but then they can't prove that, can they? [...] It is all down to trust. [...] And trying to help each other out. [...] I suppose they know who they can trust. If there is any stranger [...] or if somebody was cutting their ropes deliberately for them to lose their pots they would soon put that person in place in a way" (Partner of fisher-21).

Several aspects of trust are important to this discussion of the good fisher. First, the interviews revealed that trust - reported in the statement of fisher 19 earlier that "everybody knows the rules and stick to it" - may be built up over many years. In interviews, fishers often made reference to actions and conversations from many years ago when talking about their trust of specific fellow fishers. Second, and perhaps most significantly, is the internal policing which happens within this field. So, not only is the continual demonstration of their own trustworthiness part of cultivating and maintaining an individual's good fisher status, so too is their role in monitoring the actions of others. The interviews revealed that this took place both through maintaining a level of secrecy as well as more proactive actions. In relation to secrecy fisher 22 explained:

“You don't boast. No, that is stupid. You invite disaster if you boast. [...] You pride yourself in the good season, that you have caught well, but you, you never never boast" (F-22). 
Whilst being overtly 'showy' has, in the good farmer literature, been seen as detracting from the overall cultural capital of the farmer (Burton,2004), fisher 27 illustrated a more practical consequence that might result from being boastful about catch success:

"Like in Scarborough, there is a lot of scallopers now [...] they have been catching well apparently for years there. But now the secret is out that there is a lot of scallopers there. Everybody has gone there, [...] so that is why you don't want people to know. [...] Facebook and things like that these days. People talk” (F-27).

In using this other geographical location (on the North East coast of England), the fisher is able to illustrate how publicising catch levels can be seen as bad practice. The ability not to boast, and instead remain secretive, about the catch in their areas, was a collective endeavour and a managerial quality of a good fisher:

"Little cliques that you build up in your area is also to preserve your fishing ground as well isn't it. The stronger you are as a group to keep outsiders away the more profitable it is to be in that area" (F-16).

The extract illustrates how the collective secrecy serves to work as a strategy to keep others away from their fishing territory. It also points to the active measures taken to keep outsiders - both those not from the area, and those not seen as good fishers - away. ${ }^{13}$ Observing the activities of others fishers and monitoring any transgressions, particularly from outsiders that is, those not attuned to the specific rules of the game in this specific field - is an integral part of the system. This was evidenced, in particular, in the discussion of what fisher 28 referred to as 'flag hunters':

"You will get people that just come down and they look around for other lobster pots and they will put [their pots] there. 'Ah there is one there, I'll just lay one next to him.' [...] That is a bad fisherman. [...] Flag-hunters we call them [...] cause they just hunt flags and 'there is a flag there, there must be a lobster there"," (F-28).

This process of flag hunting was seen to be the antithesis of good fishing and the associated demonstration of skill discussed earlier. Their failure to demonstrate the necessary cultural

\footnotetext{
${ }^{13}$ Important to note is that this relationship with outsiders is couched within a policing of illegal activities by Welsh Government marine enforcement officers using fisheries patrol vessels. This ensures that only legal practices are allowed and the short-term confrontational practices such as 'dynamite fishing' noted by Walley (2010) in Tanzania are not present.
} 
capital resulted in little or no social capital amongst their fishing peers in this area. Accordingly, their field positon is such that they do not have access to the reciprocal arrangements which are central to survival in the fishing industry in this area. Fisher 28 went on to show how more overt actions may take place in some situations:

Interviewer: "so... if someone does that, flag-hunting. What can you do?"

"Pick their lobster pots up and then empty them, [...] have a word with him. [Make sure they] get shouted at. [...] Last case scenario we would cut their ropes and, you know, they obviously wouldn't come back" (F-28).

Although relatively few fishers gave examples of actually having taken such interventions, several pointed to other 'aggressive' behaviour that they would take to keep outsiders out of their territory:

"What I tend to do it that you increase your levels of fishing to try and make it unviable to be alongside you. You try to fish better than they are, so they think 'what is the point of being here'?" (F-16).

"If someone does come into our area, we just put a load of pots around their pot... so they can't fish for it anyway. Or just pick them up and open their cages. And then they know that, okay, hang on a minute, someone has picked this up..." (F-28).

Central to these examples is how accrued capital allows fishers to defend their territory. Being able to 'put pressure' on these newcomers requires both help from other fishers - that is, they need to draw on their social capital in order to crowd out interveners - as well as having sufficient additional fishing gear (or objectified cultural capital) to enable this practice. Important to note is that these outsiders are never totally excluded and interviewees relayed examples of encroachment into 'their' area. Whilst physical restriction was not possible, the prevention measure of keeping stories of large catches (which might vary over time across the peninsula) and not giving access to the resource of trust helped, in the main, keep widespread encroachment down.

A third, and interrelated, aspect of this system is that trust, the interviews showed, relates not just to the practices of fishing itself. One of the key areas where it is important to have high levels of social capital through reciprocal support was through maintaining safety at sea: 
"Maybe tomorrow I go out at sea and my boat engine breaks down. [...] I might rely on someone who take me to rescue, to help me. [...] If I help someone out one day, maybe they have done the most stupid thing in the world, but you never tell them, you just help them. Yeah. It is important. [...] You have got to realise that. [...] The best safety rules around are friends. People that watch out for you. [...]. Something breaks on one of my gear. I don't have the part immediately, but I know someone that does. I ask him 'can I have it and I'll get you one back'. He says yes, and I get it. [...] Then I give it back. If somebody is in trouble they ask me to borrow something, I say yes of course you can. [...] It is a self-preservation, but it is also common sense. [...] The community of fishermen is important, it is more important cause your life may depend on it" $(F-22)$.

Such sentiments were common across all interviews and reveal the cyclical nature of this trust and how the 'rules of the game' become internalised within the fishing habitus for this area. Not stealing catch, or interfering with the fishing gear of others leads to trust and the positioning as a good fisher. Such activities, and their contribution to good fisher status, are central to perhaps the most fundamental reciprocal resource - the help of others fishers if needed at sea.

\subsection{Sustaining the sea}

The insights from the previous sections are useful for understanding the management and future of fishing in this area. Turning back to the good farmer literature, it has been suggested that policies for management may be 'culturally unsustainable' (Burton and Paragahawewa,2011), particularly where they limit the generation and demonstration of social and cultural capitals. At the time of interviewing, the Llŷn peninsula had been subject to an attempt to introduce $\mathrm{MCZ}$ which would have resulted in the cessation of fishing activity within the designated areas but which, following public consultation, was dropped. This event was at the forefront of fishers' narratives during their interviews and is useful to consider how the good fisher framing might help us understand their reaction to the MCZ proposals. Whilst the media attention at the time focussed on more general concerns for the potential financial loss to fishers and wider communities (Dearden,2012) the interviews brought forward more subtle nuances of how fishers argued against the MCZ proposals - in particular relating to the problems of zoning and the knowledge conflicts associated with the proposals. The two following quotes illustrate the challenge offered to zones: 
"I would only lose a small area of my fishing. But there were some fishermen that fished all in that area. And those were very angry. And I can understand it as well. 'Cause you couldn't say, 'well I go there', that is full already, there are five fishermen there, 'oh, I'll go there' there is three there. So there is no space for people to move sideways" (F-18).

"yeah it would have caused conflict probably when people are moving into somebody else's area ... war at sea then" (F-8).

The quotes show that a key issue in trying to introduce MCZs was the complexity and rigidity of the system already in place. As suggested earlier in the paper, cultural capital might be derived from avoiding overlapping activities with those of other good fishers in the area and, more significantly, active sanctions might be taken in order to keep people moving into new areas. As fisher 12 notes there is, accordingly "no space for people to move sideways". Even where new territories might be available, the interviews revealed that the ability to demonstrate place-specific embodied cultural capital and understandings of these areas is no simple or short-term task and their positioning there would thus be precarious. In not having good fisher status in this new area - and hence a claim to social standing there - they would be less able to defend their fishing position against others and hence lead to the possibility, as fisher 8 suggested, of "war at sea" in the area.

Not only was the concern amongst fishers about the consequence of shifting territories, but also the potential rupture of the social relations seen to be central to their functioning as fishers in this area:

"And once you stop people fishing there, you know, you would break that relationship. Would they then turn around in 20 years' time? 'Actually this doesn't work.' [...] Who would come back then? Who would be left to fish there? You know. You would have affected the community so much. [...] That link with it. It would be lost for ever I think" (F-22).

Fisher 22's reference to "break that relationship" is telling - here the concern was not simply focussed on financial loss, but also the importance of reciprocal arrangements, intergenerational ties and knowledge transfer within the area. His interview went on to highlight the cumulative nature of these relations. They were not something, he suggested, that could be replicated or redrawn easily and once one element of this changes, the whole 
system can be irrevocably damaged. A key aspect in both of these examples is that of relevant knowledge. Such knowledge of specific areas might be seen as a 'cultural competence' which, as Bourdieu (1984, p.245) suggests, “yields profits of distinction for its owner". Several fishers used this knowledge to draw distinction between their own understanding and that embodied within MCZ proposals, with two approaches apparent. First was to challenge the assumption that their existing fishing practices were environmentally deleterious:

"Cause, who has the right? Somebody that has a piece of paper, yeah. That doesn't even know the area, I don't think so. That doesn't make sense to me. [Laugh]. Yeah... we look after it I think. Without us it would be in worse state” (F-19).

"If a scientist has found a rare sea urchin, well, how long has the fisherman been there? Years and years. How many generations? Surely that fisherman hasn't done any harm to that sea urchin, or it wouldn't be there would it. That is my opinion. You know" (F-10).

The interviews revealed that their longevity in the area was seen by fishers as testament to their good fishing abilities (cf. Sutherland and Darnhofer,2012 for agriculture). In interviews, the fishers discursively placed this longevity alongside the high environmental status of the proposed MCZ in order to position their fishing practices as not detrimental. An interrelated approach was a questioning of the science and policy makers - or what, borrowing Morris' (2006) terminology, might be referred to as 'policy knowledge culture' surrounding MCZs. At one level, there were those who suggested there MCZs represented a "blanket ban with no evidence at all” (F-12). At another level, were those such as fisher 10 who questioned the context specific nature of the knowledge on which the MCZ proposal drew:

“They were quoting European, and other 'success-stories' [...] most of them were either from California or Australia for example. The difference there is that you have got huge areas. A lot of the areas weren't fished because they are so remote anyway. [...] In Wales here, you have got a lot of coastline. [...] And from evidence coming from Lundy, where they have closed, their idea was that if we close an area it would then sort of help restore and replenish other parts with over spill kind of theory. Which was complete nonsense, cause we all know that [...] lobster are territorial, they don't move, crab as well, they don't move much, they migrate more than lobster, 
but lobster they stay in their own area, we know that from our experience fishing. They totally disregarded our views" (F-10).

Fisher 10 shows a similar critique to that shown in the literature relating to farming which considers the decontextualized and placeless nature of scientific understandings and how these may be odds with the more experiential and contextual knowledge of good farmers (Burgess et al.,2000). Fisher 10 does this by highlighting both the physical differences to the regions on which the scientific 'evidence' was based and the different cultures of fishing within these areas. Important for our broader understanding is that in the same way social status is afforded to fishing for knowing the specificities - such as micro-climate or particular species - of their area, so too it is the same logic applied to those attempting to govern fisheries. Not being 'local', these interviews suggested, amounted to not having legitimacy in the fishers' eyes, to comment on the management in the area. In terms of managing to challenge the legislation, it was important that the fishers had built up stocks of social capital in these areas - both through long-term residential and familial connection and, more importantly, through having an active and ongoing experiential understanding of the marine environment under question.

\section{Conclusions}

The paper opened with reference to Sønvisen's (2014, p.194) recognition of the need to understand fishers as more than just "myopic and short-run profit maximizers". Through a focus on 'good fishing', as defined by fishers' interviews, this paper has seen how cultural and social capital(s) are central to the functioning of fishing and intersect with fishers' generation of economic capital. Drawing on the good farmer literature has enabled several insights to be developed. Foremost, is a recognition that the dynamic, fluid and varying nature of the sea - as a field of activity for fishers - means that demonstrating the necessary facets of being a good fisher is complicated. Unlike industries such as agriculture, where farmers may be (implicitly) assessed by neighbours as well as other passers-by, the sea enables a less concrete depiction of good fishing activity. As a result, it is in the subtle performance of particular activities (the demonstration of embodied cultural capital) and the handling and particular utilisation of status-giving goods such as boats and fishing gear (objectified cultural capital) through which fishers may accrue social capital. This observation is important for our wider understanding of the fishing industry on several fronts. First, is the recognition that fishing activities may be self-governing within particular 
geographical localities. As the paper has seen, the current arrangement of who fishes where and how is shaped significantly by past history. Fishing territories are often passed down through generations - not, importantly, as legally binding, but as closely tied to their fishing status over several generations. This is important for those seeking to develop fishing policies and management. On the one hand, it highlights the importance of recognising fishers' activities and decision-making over longer time horizons. Many of these fishers have been in the industry for most of their lives and often across several generations of their family, at various times supplementing this with work outside of fishing, and shows the need to recognise that short-term activity is set within the wider framework of keeping this longer fishing heritage intact. On the other hand, we see that attempts to regulate fishing territories, such as the Welsh government's attempt to introduce highly protected MCZs, will come against a complex web of pre-existing, long established and hence quite durable, social relations. A significant challenge for those seeking to manage those waters is that these social relations and forms of understanding remain largely undocumented. The interviews showed that these largely exist through verbal communication and 'gentlemen's agreements' (see also Woodhatch and Crean,1999). Indeed, fishing activities remain consciously 'secret' within the fishing community in order to maintain territories and catches.

A second and interrelated observation is the longer term sustainability of fishing in terms of new entrants (Neis et al.,2013; Power et al.,2014; Sønvisen,2013). The paper has seen that territories may be fiercely maintained, meaning that 'outsiders' are restricted both through direct (removing or destroying their gear) and indirect (out-fishing or 'crowding out') means. New entrants, within this system, are often not welcomed when they are from outside the fishing region or where they do not demonstrate the shared fishing habitus of the area. Alongside this, schemes aimed at encouraging new entrants - such as those discussed by White (2015) - might recognise the economic capital needed for 'start up' in the industry but, the paper has shown, these must also factor in the social and cultural capital which needs to be accumulated and fishers need to go through a process of socialisation in which the rules of the fishing game in this region become internalised. This latter aspect cannot be underestimated because, as the paper has seen, even where fishers do not overtly rely on reciprocal help from other fishers, it existing in the background in terms of safety - with each needing the insurance of other fishers "watching their back" in the event of breakdowns or accidents. Fishers arguably have a short window within which they might draw on the social capital of their predecessors before it fades or is eroded. Within agriculture, by contrast, a 
large acreage or well stocked farm may serve a symbol of good farming - inherited from predecessors - even when the new entrant does not actively conform to good farming ideals or demonstrate the necessary skills, and this may continue for some time before the individual loses the status of good farmer. For fishers, by contrast, the status of good fisher requires continual and active demonstration on each fishing journey.

In exploring the potential of Bourdieusian ideas to inform the discussion of fishers, and considering the parallels and differences with the good farmer literature, this paper also highlights the need for further research in this area. A first area requiring further exploration is the extent to which notions of the good fisher and the associated practices of good fishing may be geographically specific. This is a theme considered in the good farming literature (Riley,2016a; Sutherland and Darnhofer,2012) and may appear more magnified for fishing. The paper has seen that even more so than in agriculture, fishing involves a close and iterative relationship with the environment, with the need to understand the intricacies of a particular area of sea and react to any rapid changes therein. In order to comprehend and unpack the intricate and complex relations that we have explored in this paper, a logical approach has been to take an in-depth approach to a specific geographical locality - the Llŷn peninsula. This, of course, in addition to the specific fishing cultures alluded to in the paper, has particular environmental conditions which are likely to shape the fishing habitus and notions of good fishing in particular ways. Further comparative work is needed to understand how different physical and environmental conditions might, or not, lead to variations on the notions of good fishing we have observed here. Related to this, the outward demonstration of fishing skills and abilities is likely to differ for contrasting scales and types of fishing in differing localities. Furthermore, the last section of our paper considered how new policies in this case that of MCZs - can be challenged when they conflict with pre-existing notions of good fishing. Future research could usefully consider how other policies, such as quotas (the community researched in this paper was a non-quota fishery) and whether these are similarly refuted by fishers, and what the consequences of their eventual introduction are.

A second research trajectory we would suggest relates to fishing conflicts (see for example Stepanova and Bruckmeier,2013). Our case study presented here is one where the apparent shared consensus around what fishing is, and the adherence to these rules by most working in the area, leads to a somewhat settled pattern. Areas of known conflict - such as that observed between those using stationary and those using mobile fishing gear (for example Gustavsson et al.,2014; Nightingale,2013) - might be considered through the conceptual lens we have 
outlined in this paper to examine how such conflicts may be better understood and minimised. Whilst the literature on the good farmer within European agriculture has noted that access to social capital may be limited when farmers do not perform good farming activities, research from India suggests that good farmer status may be used as an exhibition of power and serve to exclude others from having sufficient resources for occupational survival (see Kumar,2016) and such contexts are worthy of further study in considering good fishing.

A third and related area is to consider potential changes to the 'rules of the game' (Bourdieu,1990) - or the code of a particular culture. Feeding on from the aforementioned changes to fishing policy, this area of research could consider how these new horizons (re)shape what it means to be a good fisher. Whilst our study has revealed a certain level of continuity in fishing patterns and tradition, it must also be recognised that fishers have also evolved - evidenced in particular through their embracement, over time, of new fishing technologies. More research is needed on how new rules of the game - in the form of technologies, policies and environmental changes for example - become internalised into the fishing habitus and what it means to be a good fisher. The good farmer literature here is instructive (Sutherland \& Darnhofer 2012; Sutherland 2013), in particular in highlighting the temporal discordance between the implementation or onset of new rules of the game and the changes in farming identities such that these new rules become seen as 'good' practice. Existing fisheries research which has touched upon this, with Palsson (1994) for example noting how the prestigious position as 'catch-king' within the Icelandic fishery became the 'quota-king' after the introduction of quotas. Findings such as these point towards a change in what skills become symbolically valued and, thus, how capitals can become displayed in a field. Moreover, the differences noted in the paper between good farming and good fishing are arguably connected to the different policy pathways that the respective industries have taken and future consideration might be given to how agricultural policies such as nonproduction related subsidies and environmental cross-compliance might be trialled within, and (re)shape, fishing. Finally, we would echo the call within the recent good farmer literature to move beyond a predominant focus on men as the principal operators in these respective industries. Whilst men are, as we have seen here, most often the ones involved in actual fishing activity, there are myriad networks which women are involved in, including supply chains, wider communities and familial relations. These others, and the role(s) they play in defining and reproducing good fishing ideals is worthy of future attention. 


\section{References}

Acheson, J.M., 1981. Anthropology of fishing. Annual review of anthropology, 275-316.

Bear, C., 2012. Assembling the sea: materiality, movement and regulatory practices in the Cardigan Bay scallop fishery. cultural geographies 20, 21-41.

Boonstra, W.J., Hentati-Sundberg, J., 2014. Classifying fishers' behaviour. An invitation to fishing styles. Fish and Fisheries 17, 78-100.

Bourdieu, P., 1984. Distinction: A social critique of the judgement of taste. Harvard Univ Press, Harvard.

Bourdieu, P., 1986. The forms of capital, in: Richardson, J. (Ed.), Handbook of Theory and Research for the Sociology of Education. Greenwood Press, New York, pp. 241-258.

Bourdieu, P., 1989. Social Space and Symbolic Power. Sociological Theory 7, 14-25.

Bourdieu, P., 1990. The Logic of Practice. Polity Press, Cambridge.

Bourdieu, P., 1998. Practical reason : on the theory of action. Stanford University Press, Stanford.

Brandth, B., Haugen, M.S., 2011. Farm diversification into tourism-Implications for social identity? Journal of Rural Studies 27, 35-44.

Bull, J., 2011. Encountering fish, flows, and waterscapes through angling. Environment and Planning A 43, 2267-2284.

Burgess, J., Clark, J., Harrison, C., 2000. Knowledges in action: an actor network analysis of a wetland agri-environment scheme. Ecological Economics 35, 119-132.

Burton, R., Kuczera, C., Schwarz, G., 2008. Exploring Farmers' Cultural Resistance to Voluntary Agri-environmental Schemes. Sociologia Ruralis 48, 16-37.

Burton, R.J.F., 2004. Seeing through the 'good farmer's' eyes: Towards developing an understanding of the social symbolic value of 'productivist' behaviour. Sociologia Ruralis 44, 195-215. 
Burton, R.J.F., Paragahawewa, U.H., 2011. Creating culturally sustainable agrienvironmental schemes. Journal of Rural Studies 27, 95-104.

Costello, C., Ovando, D., Hilborn, R., Gaines, S.D., Deschenes, O., Lester, S.E., 2012. Status and solutions for the world's unassessed fisheries. Science 338, 517-520.

Crossley, N., 2001. The phenomenological habitus and its construction. Theory and Society 30, 81-120.

Davies, B., Hodge, I., 2007. Exploring environmental perspectives in lowland agriculture: AQ methodology study in East Anglia, UK. Ecological economics 61, 323-333.

Dearden, C., 2012. Marine Conservation Zones: Protest meeting in Pwllheli.

Department For Environment, F.A.R.A.D., 2007. Fisheries 2027: A Long-Term Vision for Sustainable Fisheries. DEFRA, London.

Eden, S., Bear, C., 2011. Reading the river through 'watercraft': environmental engagement through knowledge and practice in freshwater angling. cultural geographies 18, 297 314.

Gelcich, S., Kaiser, M.J., Castilla, J.C., Edwards-Jones, G., 2008. Engagement in comanagement of marine benthic resources influences environmental perceptions of artisanal fishers. Environmental Conservation 35.

Gustavsson, M., Lindström, L., Jiddawi, N.S., de la Torre-Castro, M., 2014. Procedural and distributive justice in a community-based managed Marine Protected Area in Zanzibar, Tanzania. Marine Policy 46, 91-100.

Guyader, O., Berthou, P., Koutsikopoulos, C., Alban, F., Demaneche, S., Gaspar, M., Eschbaum, R., Fahy, E., Tully, O., Reynal, L., 2013. Small scale fisheries in Europe: A comparative analysis based on a selection of case studies. Fisheries Research 140, $1-13$.

Hardin, G., 1968. The tragedy of the commons. Science 162, 1243-1248.

Heckathorn, D.D., 2002. Respondent-driven sampling II: Deriving valid population estimates from chain-referral samples of hidden populations. Social problems 49, 11-34. 
Holloway, L., 2004. Showing and telling farming: agricultural shows and re-imaging British agriculture. Journal of Rural Studies 20.

Jentoft, S., Davis, A., 1993. Self and sacrifice: an investigation of small boat fisher individualism and its implication for producer cooperatives. Human Organization 52, 356-367.

Kumar, R., 2016. The Perils of Productivity: Making 'Good Farmers' in Malwa, India. Journal of Agrarian Change 16, 70-93.

Martindale, T., 2014. Heritage, Skills and Livelihood: Reconstruction and regeneration in a cornish fishing port, in: Urquhart, J., Aucott, T., Symes, D., Zhoa, M. (Eds.), Social Issues in Sustainable Fisheries Management. Springer, pp. 279-299.

McCay, B.J., Acheson, J.M., 1987. The question of the commons: The culture and ecology of communal resources. University of Arizona Press, Arizona.

Morris, C., 2006. Negotiating the boundary between state-led and farmer approaches to knowing nature: An analysis of UK agri-environment schemes. Geoforum 37, 113127.

Morris, C., Potter, C., 1995. Recruiting the New Conservationists: Farmers' Adoption of Agri-environmental Schmes in the UK. Journal of Rural Studies 11, 51-63.

Neis, B., Gerrard, S., Power, N., 2013. Women and children first: the gendered and generational social-ecology of smaller-scale fisheries in Newfoundland and Labrador and northern Norway. Ecology and Society 18, 1-13.

Nightingale, A., 2013. Fishing for nature: the politics of subjectivity and emotion in Scottish inshore fisheries management. Environment and Planning A 45, 2362-2378.

Nightingale, A.J., 2011. Beyond design principles: subjectivity, emotion, and the (ir) rational commons. Society and Natural Resources 24, 119-132.

Ostrom, E., 1990. Governing the Commons: The Evolution of Institutions for Collective Action. Cambridge University Press.

Palsson, G., 1994. Enskilment at sea. Man, 901-927.

Pomeroy, R.S., Berkes, F., 1997. Two to tango: the role of government in fisheries comanagement. Marine policy 21, 465-480. 
Power, N.G., Norman, M.E., Dupré, K., 2014. "The fishery went away": The impacts of long-term fishery closures on young people's experience and perception of fisheries employment in Newfoundland coastal communities. Ecology and Society 19, 6.

Reed, M., Courtney, P., Urquhart, J., Ross, N., 2013. Beyond fish as commodities: Understanding the socio-cultural role of inshore fisheries in England. Marine Policy 37, 62-68.

Richards, P., 1989. Agriculture as a performance, in: Chambers, R., Pacey, A., Thrupp, L.A. (Eds.), Farmer first: Farmer innovation and agricultural research. IT Publications, London, pp. 39-43.

Richards, P., 1993. Cultivation: knowledge or performance?, in: Hobart, M. (Ed.), An anthropological critique of development: The growth of ignorance. Routledge, London, pp. 61-78.

Riessman, C.K., 2008. Narrative methods for the human sciences. Sage.

Riley, M., 2008. Experts in their fields: farmer-expert knowledges and environmentally friendly farming practices. Environment and Planning A 40, 1277-1293.

Riley, M., 2011. Turning Farmers into Conservationists? Progress and Prospects. Geography Compass 5, 369-389.

Riley, M., 2016a. How does longer term participation in agri-environment schemes [re] shape farmers' environmental dispositions and identities? Land Use Policy 52, 62-75.

Riley, M., 2016b. Still Being the 'Good Farmer':(Non-) retirement and the Preservation of Farming Identities in Older Age. Sociologia Ruralis 56, 96-115.

Ross, N., 2015. Understanding the fishing 'community': the role of communities of the mind. Sociologia Ruralis 55, 309-324.

Salmi, P., 2015. Constraints and Opportunities for Small-Scale Fishing Livelihoods in a PostProductivist Coastal Setting. Sociologia Ruralis 55, 258-274.

Saunders, F.P., 2015. Complex Shades of Green: Gradually Changing Notions of the 'Good Farmer' in a Swedish Context. Sociologia Ruralis, n/a-n/a. 
Sønvisen, S.A., 2013. Recruitment to the Norwegian fishing fleet: storylines, paradoxes, and pragmatism in Norwegian fisheries and recruitment policy. Maritime Studies 12, 1.

Sønvisen, S.A., 2014. Contemporary fisher images: Ideologies, policies and diversity. Journal of Rural Studies 34, 193-203.

St Martin, K., 2006. The impact of "community" on fisheries management in the US Northeast. Geoforum 37, 169-184.

St Martin, K., 2007. The difference that class makes: neoliberalization and non-capitalism in the fishing industry of New England. Antipode 39, 527-549.

Stepanova, O., Bruckmeier, K., 2013. The relevance of environmental conflict research for coastal management. A review of concepts, approaches and methods with a focus on Europe. Ocean \& coastal management 75, 20-32.

Sumberg, J., 2011. 'Good farmers' in Sub-Saharan Africa: evolving narratives. Outlook on AGRICULTURE 40, 293-298.

Sutherland, L.-A., 2013. Can organic farmers be 'good farmers'? Adding the 'taste of necessity' to the conventionalization debate. Agriculture and Human Values 30, 429441.

Sutherland, L.-A., Darnhofer, I., 2012. Of organic farmers and 'good farmers': Changing habitus in rural England. Journal of Rural Studies 28, 232-240.

Sutherland, L.A., Burton, R.J.F., 2011. Good Farmers, Good Neighbours? The Role of Cultural Capital in Social Capital Development in a Scottish Farming Community. Sociologia Ruralis.

Symes, D., Frangoudes, K., 2001. The social organisation and reproduction of inshore fishing, in: Symes, D., Phillipson, J. (Eds.), Inshore fisheries management. Springer, Dordrecht, pp. 159-175.

Symes, D., Hoefnagel, E., 2010. Fisheries policy, research and the social sciences in Europe: challenges for the 21st century. Marine Policy 34, 268-275.

Symes, D., Phillipson, J., 2009. Whatever became of social objectives in fisheries policy? Fisheries Research 95, 1-5. 
Urquhart, J., Acott, T., 2013. A Sense of Place in Cultural Ecosystem Services: The Case of Cornish Fishing Communities. Society \& Natural Resources 27, 3-19.

Urquhart, J., Acott, T., Reed, M., Courtney, P., 2011. Setting an agenda for social science research in fisheries policy in Northern Europe. Fisheries Research 108, 240-247.

Van der Ploeg, J.D., 2003. The virtual farmer: Past, present and future of the Dutch peasantry. Uitgeverij Van Gorcum.

van Ginkel, R., 2014. A Texel fishing lineage: the social dynamic and economic logic of family firms. Maritime Studies 13, 1-19.

Walley, C.J., 2010. Rough waters: nature and development in an East African marine park. Princeton University Press.

Whatmore, S., Munton, R., Little, J., Marsden, T., 1987. Towards a Typology of Farm Businesses in Contemporary British Agriculture. Sociologia Ruralis 27, 21-37.

White, C.S., 2015. Getting into fishing: recruitment and social resilience in north Norfolk's 'Cromer crab' fishery, UK. Sociologia Ruralis 55, 291-308.

Williams, R., 2014. The Socio-Cultural Impact of Industry Restructuring: Fishing Identities in Northeast Scotland, in: Urquhart, J., Aucott, T., Symes, D., Zhoa, M. (Eds.), Social Issues in Sustainable Fisheries Management. Springer, pp. 301-317.

Wilson, O.J., Wilson, G.A., 1997. Common cause or common concern? The role of common lands in the post-productivist countryside. Area 29, 45-58.

Woodhatch, L., Crean, K., 1999. The gentleman's agreements: a fisheries management case study from the Southwest of England. Marine Policy 23, 25-35. 